\title{
Safe use of infliximab for the treatment of severe perianal Crohn's disease after diagnosis and treatment of lymphoma
}

\author{
Carlos Bernardes $^{1,2}\left([) \cdot\right.$ Pedro Russo $^{1} \cdot$ Diana Carvalho $^{1} \cdot$ Joana Saiote $^{1} \cdot$ Jaime Ramos $^{1}$
}

Received: 20 October 2017 / Accepted: 17 November 2017 / Published online: 22 November 2017

C Japanese Society of Gastroenterology 2017

\begin{abstract}
Inflammatory bowel disease is associated with an increased likelihood of developing lymphoma. However, it is still controversial if this risk may be attributed to the disease itself or rather represents an effect of immunosuppressive treatment. Although tumor necrosis factor alpha (TNF $\alpha)$ is a key cytokine for cancer immunosurveillance, the potential relationship between anti-TNF $\alpha$ agents and the pathogenesis of lymphoproliferative disorders remains unclear. Here, we describe the case of a patient with severe perianal Crohn's disease, treated with infliximab monotherapy, whose unusual presentation with acute groin pain required surgical intervention and led to the diagnosis of diffuse large B-cell lymphoma. However, 10 months after this episode, treatment with infliximab was restarted because the patient continued with refractory and disabling perianal disease. Currently, with a follow-up of 36 months, under infliximab $10 \mathrm{mg} / \mathrm{kg}$ every 4 weeks, he maintains mild perianal Crohn's disease and persists in sustained clinical and imaging remission of the lymphoproliferative disorder.
\end{abstract}

Keywords Lymphoma $\cdot$ Lymphoproliferative disorder $\cdot$ Crohn's disease $\cdot$ Inflammatory bowel disease $\cdot$ Infliximab $\cdot$ AntiTNF $\alpha$

\section{Introduction}

Tumor necrosis factor alpha (TNF $\alpha)$, a key mediator of inflammation, plays a crucial role in the pathogenesis of inflammatory bowel disease (IBD) [1]. In fact, TNF $\alpha$ antagonists have become widely used and have shifted the paradigm in the management of IBD over the past few years [2, 3]. Notwithstanding, TNF $\alpha$ is also critical for cancer immunosurveillance and defense against infections $[4,5]$; thus, concerns have been raised regarding the use of anti-TNF $\alpha$ therapy and the risk of certain complications, including lymphoma [6]. Crohn's disease patients have been associated with an increased risk of lymphoproliferative disorders, especially non-Hodgkin lymphoma [7]; however, it remains controversial whether this only represents a causal effect of immunosuppressive therapy or if IBD itself is an independent risk factor for lymphoma [8]. Although subjects with

Carlos Bernardes

carlosfbernardes@gmail.com

1 Gastroenterology Department, Centro Hospitalar de Lisboa Central, Lisbon, Portugal

2 Rua Alfredo Inácio Ramos da Silva, $28,3^{\circ} \mathrm{E}$, 2730-203 Barcarena, Portugal intestinal lymphomas may experience bowel complications requiring surgery, acute groin pain as the first presentation of a nodal lymphoma is extremely unlikely and has not been described before in an IBD patient. We present the case of a Crohn's disease patient, under treatment with infliximab, who was diagnosed with a nodal lymphoma after presenting with acute groin pain.

\section{Clinical case}

A 29-year-old male, with a history of recurrent perianal fistulas and abscesses, who maintained severe anal pain and perianal purulent drainage despite several surgical procedures, was referred to our center. A proctological examination under anesthesia revealed a deep ulcer in the anal canal and perianal abscess, for which incision, drainage, and seton placement were performed and antibiotics were administered. He underwent a colonoscopy that showed skip areas with decreased vascular pattern and ulceration in all colon segments and in the terminal ileum, and biopsies were taken. Histopathological analysis findings and further pelvic magnetic resonance (MR) imaging and MR enterography allowed the diagnosis of ileocolonic and complex perianal 
Crohn's disease. The patient was started on treatment with prednisolone (50 mg daily) and, given the extent and severity of the luminal and perianal involvement, a top-down strategy was adopted-infliximab $5 \mathrm{mg} / \mathrm{kg}$ was initiated (at 0,2 and 6 weeks, and thereafter every 8 weeks) shortly after steroid initiation. In the following months, since he maintained complex and disabling perianal disease and having required several surgical procedures to unroof the fistula tracts and seton placement, infliximab dose adjustment (by shortening the infusion intervals to every 6 weeks) and its combination with hyperbaric oxygen therapy were required.

In July 2014, 17 months after anti-TNF $\alpha$ initiation and while in clinical remission of luminal Crohn's disease, the patient presented to the emergency department with a 5-h history of severe pain and swelling in the right inguinal region. Upon examination, a painful bulky and non-reducible mass was found, leading to the clinical diagnosis of incarcerated right inguinal hernia, for which he underwent surgery. However, surgical exploration unexpectedly revealed a highly vascularized 5-cm lymph node with a necrotic center, without any evidence of inguinal hernia. Regional lymphadenectomy was performed and resected specimens were sent for histological and microbiological evaluation. Apart from a slight increase in C-reactive protein ( $24 \mathrm{mg} / \mathrm{L})$, initial laboratory studies, which also included complete blood count, erythrocyte sedimentation rate, renal and liver function tests, lactate dehydrogenase, creatine kinase and Epstein-Barr virus serologies, were unremarkable. Further histological analysis of the enlarged lymph node described the presence of architectural distortion and diffuse infiltration of large atypical lymphocytes, with irregular nuclei, some of which with visible nucleoli (Fig. 1). The immunohistochemistry profile (CD20+, CD3-, Bcl-6+, CD10-, MUM-1-, Bcl$2-)$ was compatible with diffuse large B-cell lymphoma of germinal center B-cell-like subtype (Fig. 2). The remaining resected lymph nodes did not show histological features of

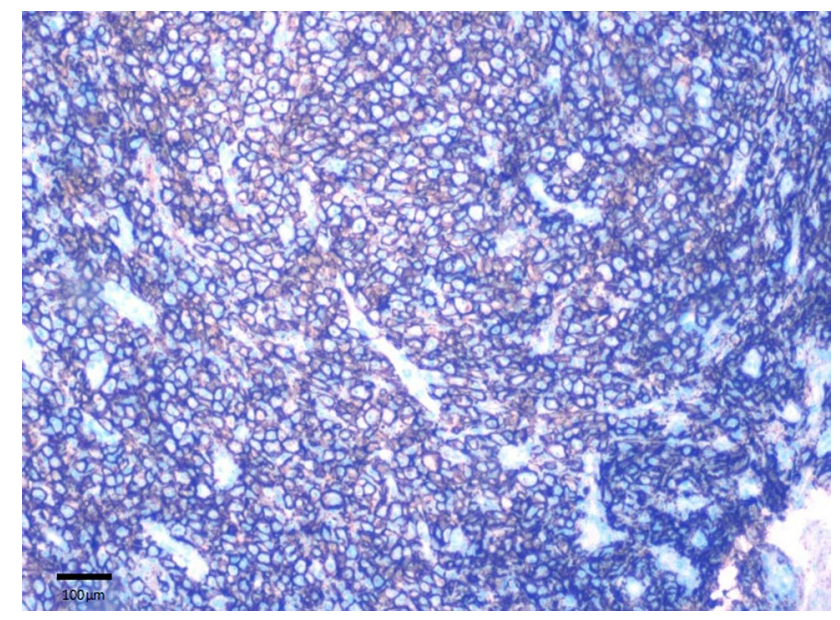

Fig. 2 Immunohistochemistry staining for Bcl-2 (×200)

malignancy. Additional investigation included bone marrow biopsy, full body computed tomography (CT) scan, positron emission tomography-CT and measurement of beta-2-microglobulin, which were all normal. The post-procedure course was uneventful and he was discharged being completely asymptomatic. A multidisciplinary approach was undertaken which included representatives from the hematology team who advised that chemotherapy in a patient with persistent perianal suppuration could result in an extremely high risk of infectious complications. Therefore, given his staging (Ann Arbor stage I) and clinical features and the involvement of a single lymph node, it was decided not to perform chemotherapy. Anti-TNF $\alpha$ therapy was suspended and the patient was kept under observation and close monitoring. In the following months, he developed recurrent perianal supuration despite antibiotics, topical treatment and hyperbaric oxygen therapy. Approximately 10 months later, since he continued with severe and disabling perianal
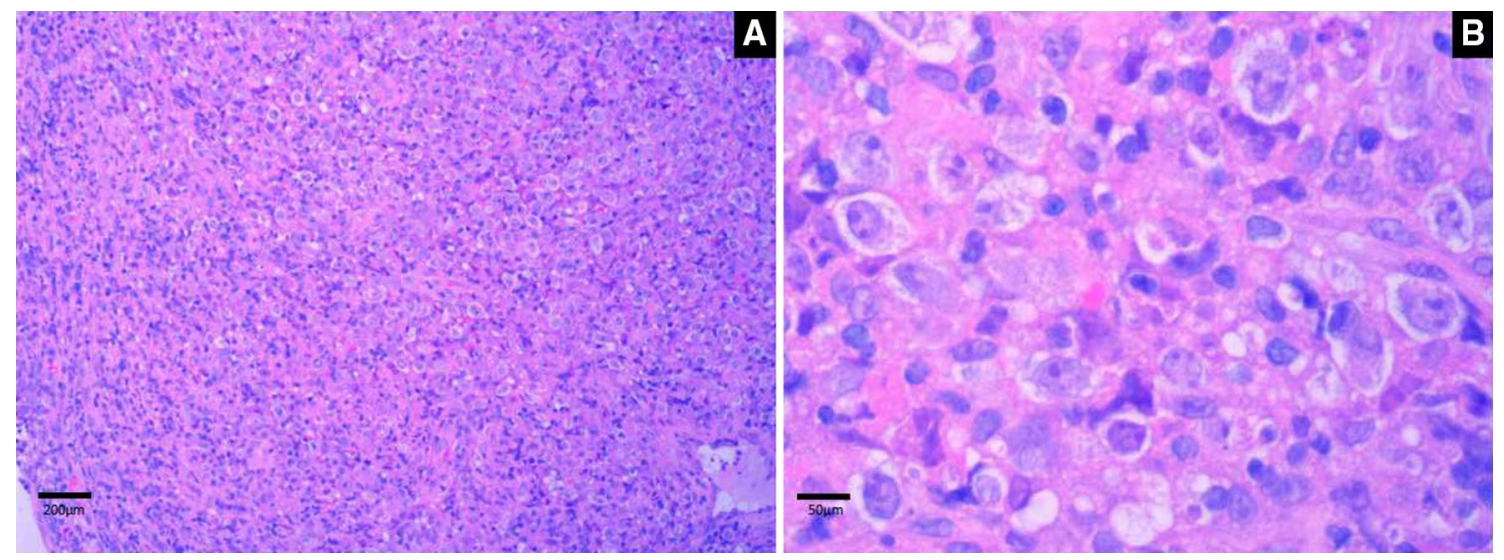

Fig. 1 a, b Lymph node revealing diffuse infiltration of large atypical cells, with irregular nuclei and visible nucleoli (H\&E stain; a $\times 100$, b $\times 400)$ 
involvement, the difficult decision of restarting infliximab therapy was taken, after discussion with the hematology team and careful consideration of the risks and benefits. Currently, with a follow-up of 36 months, under infliximab $10 \mathrm{mg} / \mathrm{kg}$ every 4 weeks, he maintains mild perianal Crohn's disease and persists in sustained clinical and imaging remission of the lymphoma (Fig. 3).

\section{Discussion}

In the Western world, there has been an upward trend in the incidence of lymphoma in the past few decades, along with a parallel increase in the occurrence of inflammatory conditions treated with immunosuppressive agents [9]. Various studies have identified an increased risk of lymphoma among patients with several chronic inflammatory disorders $[10,11]$. Persistent activation of the immune system may exert a critical influence in the genesis of lymphoproliferative disorders; chronic B-cell stimulation and proliferation, in particular, appear to pose a significant threat [12]. With regard to IBD, some controversy still exists concerning the contribution of this disease to the occurrence of hematological malignancies. Although large population-based studies did not show a correlation between IBD and such conditions, a meta-analysis conducted by Pedersen et al. suggested that
Crohn's disease patients would have a borderline significant increase in the likelihood of developing a lymphoma [13-15]. These latter results were corroborated by a subsequent population-based study which revealed an association between Crohn's disease and non-Hodgkin lymphoma, unrelated to thiopurine exposure [7]. Additionally, advanced age, male gender, genetic mutations, certain viral infections and, most importantly, immunosuppressive therapy, were identified as risk factors for developing lymphoproliferative disorders in IBD patients [8]. In fact, despite remaining uncertainties regarding the potential independent role of the disease itself in the pathogenesis of those disturbances, the contribution of immunosuppressive therapy is widely known. Patients treated with thiopurines were shown to have a 4- to 5-fold increase in the risk of acquiring lymphoma, with this risk being correlated with the duration of treatment and being eliminated after its cessation [16, 17]. Regarding anti-TNF $\alpha$ therapy, apart from the case of hepatosplenic T-cell lymphoma, for which they seem to potentiate the deleterious effect of thiopurines, there is not enough evidence to claim that these agents may contribute to lymphoma occurrence [8]. Both a systematic review of registries and prospective observational studies of rheumatoid arthritis patients and an analysis of the Crohn's Therapy, Resource, Evaluation and Assessment Tool (TREAT) registry did not verify a higher probability of such complications among

\section{Clinical course}

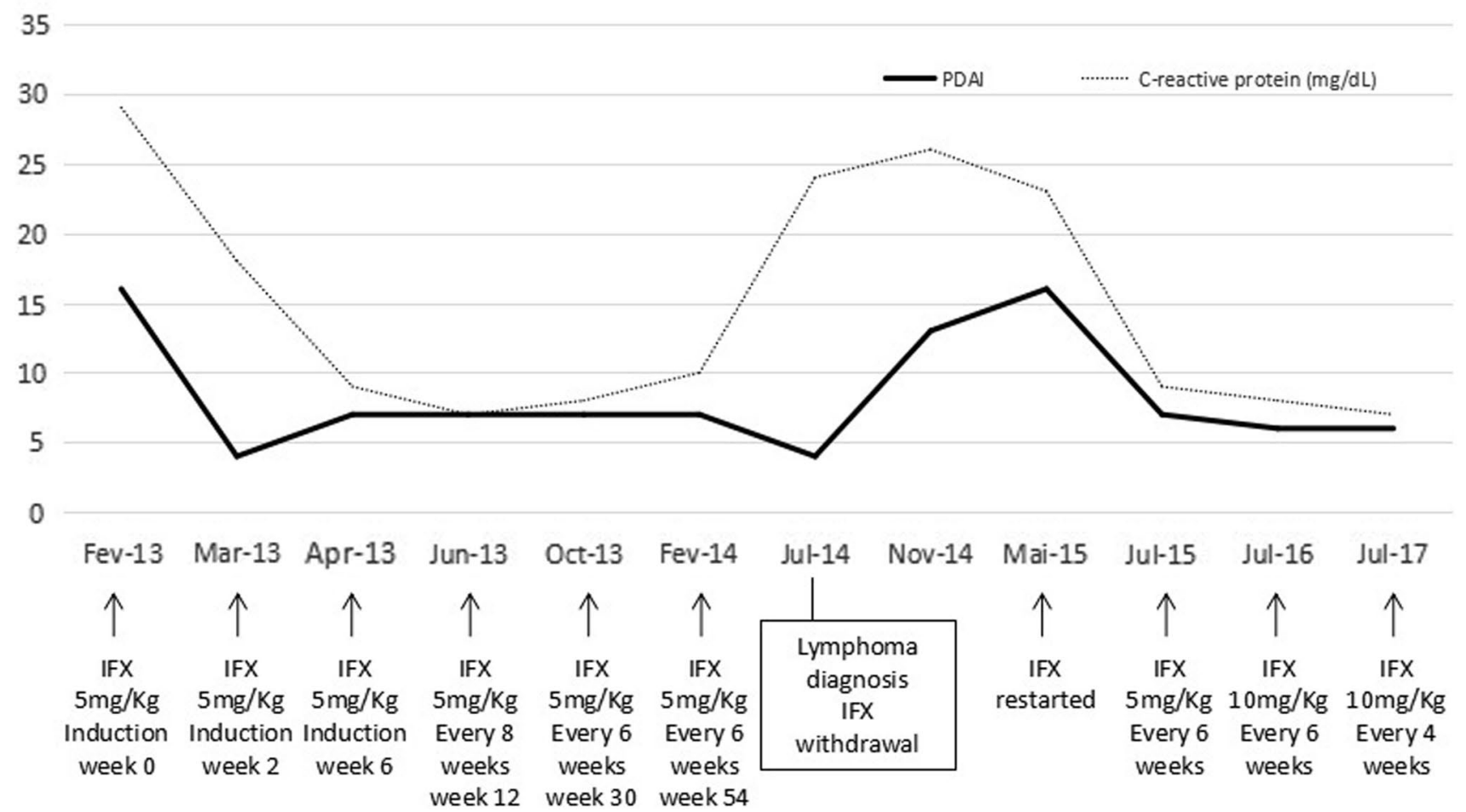

Fig. 3 Clinical course of the patient [PDAI perianal disease activity index, C-reactive protein (mg/dL) and treatment (IFX infliximab)] 
subjects who underwent anti-TNF $\alpha$ treatment $[18,19]$. Thus, in a patient like ours, who was submitted only to anti-TNF $\alpha$ therapy and has never been exposed to thiopurines, the possible association between treatment and these malignancies is even more doubtful.

Diffuse large B-cell lymphoma (DLBCL) accounts for approximately one-third of adult non-Hodgkin lymphoma cases and usually presents with palpable lymphadenopathies or extranodal involvement [20,21]. Since the gastrointestinal tract is a frequent extranodal site of involvement in nonHodgkin lymphomas (the most common in DLBCL), diagnosis often occurs following surgery for any abdominal complication, such as intussusception, acute appendicitis, bowel perforation, obstruction or even ischemia due to mesenteric thrombosis [22-26]. Although DLBCL frequently shows a rapid proliferation rate, it is surprising that this phenomenon could be sufficient to manifest itself as an acute phenomenom, such as in our patient, whose initial presentation with an extremely painful bulky and non-reducible mass, which started only a few hours before admission, simulated an incarcerated inguinal hernia and led to surgery.

Several authors have reported spontaneous regression of lymphoma after immunosuppressive therapy withdrawal [27-31]. Nonetheless, we did not find any case in the literature of anti-TNF $\alpha$ resumption in this setting. The available evidence is still insufficient to warrant the safety of such drugs in patients with a background of hematological malignancy. However, in a patient like ours, with persistently active and severely disabling perianal Crohn's disease, the difficult decision to reinitiate biological therapy has ensured clinical improvement without relapse of the lymphoproliferative disorder during the follow-up period.

\section{Compliance with ethical standards}

Conflict of interest All authors declare no conflicts of interest.

Human rights All procedures followed have been performed in accordance with the ethical standards laid down in the 1964 Declaration of Helsinki and its later amendments.

Informed consent Informed consent was obtained from all patients for being included in the study.

\section{References}

1. Papadakis KA, Targan SR. Role of cytokines in the pathogenesis of inflammatory bowel disease. Annu Rev Med. 2000;51:289-98.

2. Kim DH, Cheon JH. Pathogenesis of inflammatory bowel disease and recent advances in biologic therapies. Immune Netw. 2017;17(1):25-40.

3. Levin AD, Wildenberg ME, Gijs R, et al. Mechanism of action of anti-TNF therapy in inflammatory bowel disease. J Crohns Colitis. 2016;10(8):989-97.
4. Wajant H. The role of TNF in cancer. Results Probl Cell Differ. 2009;49:1-15.

5. Minozzi S, Bonovas S, Lytras T, et al. Risk of infections using anti-TNF agents in rheumatoid arthritis, psoriatic arthritis, and ankylosing spondylitis: a systematic review and meta-analysis. Expert Opin Drug Saf. 2016;15(Sup1):11-34.

6. Lakatos PL, Miheller P. Is there an increased risk of lymphoma and malignancies under anti-TNF therapy in IBD? Curr Drug Targets. 2010;11(2):179-86.

7. Jess T, Horváth-Puhó E, Fallingborg J, et al. Cancer risk in inflammatory bowel disease according to patient phenotype and treatment: a Danish population-based cohort study. Am J Gastroenterol. 2013;108(12):1869-76.

8. Magro F, Peyrin-Biroulet L, Sokol H, et al. Extra-intestinal malignancies in inflammatory bowel disease: results of the 3rd ECCO Pathogenesis Scientific Workshop (III). J Crohns Colitis. 2014;8(1):31-44.

9. Bichile T, Petri M. Incidence of lymphoma associated with underlying lupus: lessons learned from observational studies. Curr Opin Rheumatol. 2014;26(2):111-7.

10. Bernatsky S, Boivin J-F, Joseph L, et al. An international cohort study of cancer in SLE. Arthritis Rheum. 2005;52(5):1481-90.

11. Ekström $\mathrm{K}$, Hjalgrim $\mathrm{H}$, Brandt L, et al. Risk of malignant lymphomas in patients with rheumatoid arthritis and in their first degree relatives. Arthritis Rheum. 2003;48(4):963-70.

12. Sokol H, Laurent B. Lymphoma risks in IBD. In: Bayless TM, Hanauer S, editors. Advanced therapy in inflammatory bowel disease. volume I: IBD and ulcerative colitis. 3rd ed. Shelton: People's Medical Publishing House; 2011. p. 489-97.

13. Chiorean MV, Pokhrel B, Adabala J, et al. Incidence and risk factors for lymphoma in a single-center inflammatory bowel disease population. Dig Dis Sci. 2011;56(5):1489-95.

14. Lewis JD, Bilker WB, Brensinger C, et al. Inflammatory bowel disease is not associated with an increased risk of lymphoma. Gastroenterology. 2001;121(5):1080-7.

15. Pedersen N, Duricova D, Elkjaer M, et al. Risk of extraintestinal cancer in inflammatory bowel disease: meta-analysis of population-based cohort studies. Am J Gastroenterol. 2010;105(7):1480-7.

16. Beaugerie L, Brousse N, Bouvier AM, CESAME Study Group, et al. Lymphoproliferative disorders in patients receiving thiopurines for inflammatory bowel disease: a prospective observational cohort study. Lancet. 2009;374(9701):1617-25.

17. Khan N, Abbas AM, Lichtenstein GR, et al. Risk of lymphoma in patients with ulcerative colitis treated with thiopurines: a nationwide retrospective cohort study. Gastroenterology. 2013;145(5):1007-15.

18. Mariette X, Matucci-Cerinic M, Pavelka K, et al. Malignancies associated with tumour necrosis factor inhibitors in registries and prospective observational studies: a systematic review and metaanalysis. Ann Rheum Dis. 2011;70(11):1895-904.

19. Lichtenstein GR, Feagan BG, Cohen RD, et al. Serious infection and mortality in patients with Crohn's disease: more than 5 years of follow-up in the TREAT ${ }^{\mathrm{TM}}$ registry. Am J Gastroenterol. 2012;107(9):1409-22.

20. Menon MP, Pittaluga S, Jaffe ES. The histological and biological spectrum of diffuse large B-cell lymphoma in the WHO classification. Cancer J. 2012;18(5):411-20.

21. Møller MB, Pedersen NT, Christensen BE. Diffuse large B-cell lymphoma: clinical implications of extranodal versus nodal presentation - a population-based study of 1575 cases. Br J Haematol. 2004;124(2):151-9.

22. Flynn AD, Azar JM, Chiorean MV. Spontaneous regression of colonic lymphoma following infliximab and azathioprine withdrawal in patients with Crohn's disease. Inflamm Bowel Dis. 2013;19(5):E69-70. 
23. Khanna M, Buddhavarapu SR. Primary Burkitt's lymphoma of the appendix presenting as acute abdomen: a case report. J Radiol Case Rep. 2008;2(5):9-14.

24. Boscà-Robledo A, Pous-Serrano S, García-Mayor RL, et al. Acute abdomen as the first manifestation of a post-transplant lymphoproliferative disorder. Int J Colorectal Dis. 2011;26(8):1081-2.

25. Negrean V, Graur F, Moiş E, et al. Ileocecal obstruction due to B-cell non-Hodgkin lymphoma. Chirurgia (Bucur). 2016;111(1):71-3.

26. Ishii $\mathrm{W}$, Ito $\mathrm{S}$, Kondo $\mathrm{Y}$, et al. Intravascular large B-cell lymphoma with acute abdomen as a presenting symptom in a patient with systemic lupus erythematosus. J Clin Oncol. 2008;26(9):1553-5.

27. Flynn AD, Azar JM, Chiorean MV. Spontaneous regression of colonic lymphoma following infliximab and azathioprine withdrawal in patients with Crohn's disease. Inflamm Bowel Dis. 2013;19(5):E69-70.
28. Cassaday RD, Malik JT, Chang JE. Regression of Hodgkin lymphoma after discontinuation of a tumor necrosis factor inhibitor for Crohn's disease: a case report and review of the literature. Clin Lymphoma Myeloma Leuk. 2011;11(3):289-92.

29. Mo N, Murthu S, O'Sullivan M. Regression of lymphoma after withdrawal of infliximab alone in an infliximab/methotrexatetreated RA patient. Rheumatology. 2011;50(4):808-10.

30. Thonhofer R, Gaugg M, Kriessmayr M, et al. Spontaneous remission of marginal zone B cell lymphoma in a patient with seropositive rheumatoid arthritis after discontinuation of infliximabmethotrexate treatment. Ann Rheum Dis. 2005;64(7):1098-9.

31. Komatsuda A, Wakui H, Nimura T, et al. Reversible infliximabrelated lymphoproliferative disorder associated with Epstein-Barr virus in a patient with rheumatoid arthritis. Mod Rheumatol. 2008;18(3):315-8. 